\title{
Las escuelas y principales corrientes del derecho penal en la legislación salvadoreña
}

\author{
Oswaldo Feusier \\ Universidad Centroamericana \\ "José Simeón Cañas"
}

Resumen: El artículo repasa las principales líneas ideológicas de las codificaciones penales salvadoreñas hasta la legislación penal previa a 1974. Se estudiarán dos tendencias dominantes en dicho periodo de tiempo: 1) El modelo penal clásico o liberal, sobre todo presente en los codificaciones hasta 1904, y 2) El modelo penal positivista y el Derecho penal de autor, dominante a lo largo de la gran mayoría del siglo XX en nuestro país. En un próximo artículo estudiaremos otras tendencias principalmente presentes en las codificaciones de 1974 hasta 1998.

Palabras clave: Derecho penal, tendencias ideológicas, positivismo, liberalismo.

Abstract: The purpose of this article is to review the principal ideologies of the salvadorian penal codes up to the penal legislation of 1974. We will study the two dominant tendencies in that period of time: 1) the classical penal code or liberal, overall present in the penal code up to 1904, and 2) the positivism model and the criminal law of author, dominant throughout most of the XX century in our country. In the next number, we will study other tendencies in the codification from 1974 up to 1998.

Keywords: Criminal law, ideological tendencies, positivism, liberalism. 


\title{
Introducción
}

\begin{abstract}
"Tres palabras rectificadoras ciencia, libreras enteras de especuladel legislador, y bibliotecas enteras ciones jurídicas caen hechas añicos. se convierten en inútiles pliegos Welzel, principal formulador de la impresos", tres palabras modifica- influyente doctrina finalista en el doras y en los términos delineados Derecho penal, no estaba de acuerdo por Hermann von Kirchmann en su famosa conferencia de 1947, La falta de valor de la jurisprudencia como con la anterior afirmación y desde su Derecho Penal de 1956 supo dar respuesta a Kirchmann:
\end{abstract}

\begin{abstract}
Es creencia errónea positivista la que supone que el derecho en su integridad es un producto del legislador; que el legislador puede administrar arbitrariamente la materia jurídica y que la dogmática jurídica es, por tanto, sólo la elaboración técnica de esta materia jurídica "casual" [...] El libro presentado está en posición diametralmente opuesta a semejante concepción del derecho y de la ciencia jurídica. Parte de la convicción de que el legislador no es en manera alguna omnipotente, y que está ligado a determinados límites dados en la materia del derecho. Encontrar y llevar al conocimiento estos límites, es la misión de una tarea científica en derecho penal. (Welzel, 1956, p. 8.)
\end{abstract}

Frente a la omnipotencia del legislador, Welzel opuso ciertas realidades "lógico objetivas" que deben preceder cualquier análisis o estudio jurídico, realidades impresas desde siempre en la naturaleza de las cosas que deben ser respetadas por el legislador, y a la vez descubiertas y protegidas por el jurista o el investigador del Derecho, siendo una de estas estructuras "lógico objetivas" la constitución finalmente dirigida del actuar humano, una formulación que cambiará el entendimiento del delito por las próximas décadas en toda la zona de influencia de la tradición continental europea, incluyendo nuestro pequeño país.

De hecho, casi 40 años después de la publicación de Welzel, la exposición de motivos del Código penal de 1998 estaría aceptando uno de los postulados fundamentales del finalismo; uno que se repite mecánica e irreflexivamente en prácticamente todo requerimiento fiscal y resolución definitiva judicial:

El anteproyecto toma los postulados de la posición mayoritaria de la doctrina actual adoptando la clasificación del error de tipo 
y de prohibición [...] Esta posición es acorde con los postulados de la doctrina finalista de la acción, la cual distingue entre un dolo natural, integrante de la tipicidad, referida entonces al aspecto objetivo de ella y por tanto relacionado con un error sobre ese aspecto objetivo. (Asamblea Legislativa, Exposición de motivos, Código penal de 1998)

Basta leer el fragmento anterior, para caer en la cuenta de la inconsistencia entre la justificación de la exposición de motivos y los fundamentos brindados por Welzel. Este último, una suerte de iusnaturalista de su época, plantaba cara contra la todavía potente influencia del positivismo formalista de su época, enfrentándose contra un legislador que le parecía omnipotente y que, en parte, consideraba responsable de la devastación que azotaba Europa en las medianías del siglo XX. Por su parte, la exposición de motivos de 1998, acepta el finalismo porque se trataba de "la posición mayoritaria de la doctrina actual", una aceptación sin convencimiento, sin un interés de dialogar con los postulados del autor, de comprenderlos, se trata más bien de una repetición acrítica común en la codificación latinoamericana:

La codificación penal de América Latina presenta un mosaico de elementos ideológicos provenientes de Europa, que algunas veces son casi supervivencias, lo que da la sensación de un conjunto poco ordenado de dinosaurios vivos y computadoras, que resulta de la importación de textos - a veces parciales de los códigos de modelos continentales europeos. (Zaffaroni (2000, p. 22)

Si esto es así, caemos en la cuenta de la importancia por la reflexión jurídica crítica y profunda de los principales filones que alimentan nuestro pensamiento jurídico en general, una labor que desafortunadamente se encuentra pendiente en la mayoría de facultades de Derecho de nuestro país, más ocupadas en las labores de docencia que las de investigación, en la replicación acrítica del conocimiento que en la creación del mismo. ${ }^{1}$ En el campo penal, un paso por lograr esta reflexión fue dado por Miguel Alberto Trejo, quien describió en su Curso de Derecho Penal Salvadoreño (Trejo, 2002, pp. 216-239) las principales características en la evolución de nuestra codificación penal desde la época colonial hasta nuestros días.

Pero lo anterior no es suficiente, el presente esfuerzo pretende ir más allá de lo descriptivo, tratando de 
identificar las principales influencias ideológicas reconocibles en el largo devenir de nuestra legislación penal; una historia de las ideas en el ámbito penal, trabajo limitado por lo ingente de su objeto, por el escaso material disponible a nuestro alcance y por la poca formación en investigación histórica del autor, pero sin duda, un esfuerzo necesario, si es que deseamos algún día conformar un pensamiento jurídico propio, auténticamente nacional y no una mala digestión del extranjero. Nunca podremos alcanzar la originalidad y profundidad deseada si antes no comprendemos las bases sobre las cuales hemos construido y caminado.

En dicho afán, y luego de un estudio de nuestra legislación penal punitiva previa al Código penal de 1998, considero que puede vislumbrarse una evolución en el cual participa el siguiente mosaico de ideas.

\section{Primeras codificaciones penales: la implantación del modelo liberal y presencia de la escuela clásica}

El iluminismo representó, entre muchas cosas, un rompimiento sustancial con los parámetros de legitimación del poder político monárquico, con una visión del poder que deja de justificarse desde arriba, con la apelación a las tradiciones y la voluntad divina, y que de ahora en adelante tratará de legitimarse "desde abajo"; desde el individuo en sociedad, auténtica signataria del contrato social que plasma su voluntad en la ley a través de sus representantes.

Con la ilustración, el poder político - y dentro de éste el penal - encontrará nuevas limitantes basadas en el reposicionamiento del ciudadano frente al poder, y en esta nueva situación de privilegio, no podrá ser objeto de restricciones, sin proceso previo, de penas inhu- manas o procesos arbitrarios, de condenas basadas en interpretaciones analógicas o antojadizas de la ley, surgiendo la mayoría de garantías y derechos que limitan al poder penal, y que damos por sentados en los primeros artículos de nuestros Códigos penales hasta la fecha.

El hervidero de ideas que representó el pensamiento ilustrado sería trasladado al ámbito del Derecho penal de la mano de varios pensadores que abogaron por la "racionalización" del poder punitivo del Estado, autores como John Howard y su Estado de las cárceles en Inglaterra y Gales (1782), en el cual realiza una ácida crítica al sistema carcelario de la época; Cayetano Filangieri y su Ciencia de la legislación (1788); Paul Ritter von Feuerbach y su Teoría del impulso psíquico; Karl Hommel y su 
Recompensa y pena conforme a las leyes turcas (1770), y no puede olvidarse la influencia de Manuel de Lardizábal y Uribe, quien en 1782 publicó su Discurso sobre las penas, obra que diseminó el pensamiento jurídico penal de la ilustración en América y España (Domingo, 2004, pp. 700-702).

Sin embargo, el nombre más representativo en este re-pensar el contenido del Derecho penal, fue el del filósofo, literato, economista y jurista, Cesare Bonesana marqués de Beccaria, quien en 1764 publicó de forma anónima su Dei delitti e della pene (De los delitos y de las penas), en el cual deja sentir toda la influencia recibida del pensamiento francés de la época, resonando D’Alambert, Diderot, Helvecio, Buffon, Hume, entre otros.

En De los delitos y de las penas desarrolló de forma pormenorizada muchos de los principios, instituciones y garantías constitucionales que actualmente damos por sentadas en nuestras cartas magnas a la hora de limitar el poder de castigar: La ley como único medio de formular la norma penal (principio de legalidad), lo tiránico de la violencia pública que no surja de la estricta necesidad (principio de mínima intervención), la vocación utilitaria y social de las penas (teorías de la prevención), la proscripción de las normas oscuras o ambiguas (otra faceta del principio de legalidad), la necesidad de proporción entre la violencia de la pena y la violencia del delito penado (principio de proporcionalidad), la prohibición de jueces o comisiones especiales y las acusaciones secretas (garantía del juez natural y, en parte, del derecho de defensa), la crueldad del tormento y la tortura en la tramitación del proceso, la prontitud y la humanización de las penas, entre otras ideas.

Con el tiempo, el pensamiento penal de la ilustración se sistematizó en una serie de axiomas y principios básicos, surgiendo la "Escuela clásica" del derecho penal, etiqueta creada $a$ posteriori por los detractores de estos autores, y dentro de la cual se aglutinaba una variopinta gama de penalistas con diferentes planteamientos (Carrara, Rossi, Filangieri, Pacheco, Pagano, Pessina, entre otros), que a pesar de lo antagónico de sus posiciones en ciertos puntos, parecían coincidir en los siguientes:

1. Una visión del castigo cimentada en el libre albedrío del perpetrador del delito, que es una decisión o expresión de la voluntad, y quien tomó tal decisión debe hacerse cargo de la misma, no hay ninguna dificultad en hablar de la "culpabilidad" que demuestra el delincuente por su hecho, y sólo la persona libre puede reputarse como culpable. Quien no es libre no es culpable, y por ende no merece pena, o quien es menos libre, 
será menos culpable recibiendo una sanción atenuada.

2. La principal, sino única reacción del derecho penal es la pena, que tiene un carácter de "mal" que se impone sobre el mal realizado por el perpetrador del delito. Todavía hasta nuestros días, la palabra pena significa "Castigo", "aflicción", "dolor" o "tormento" (RAE). La finalidad de esta pena puede variar entre ser una justa retribución por el acto libremente realizado, o un fin preventivo de restablecer el orden social mediante la intimidación de potenciales delincuentes, o redención del delincuente a través del trabajo, aunque los autores "clásicos" debaten ávidamente sobre este punto, todos dan por sentado el carácter aflictivo de la pena.

3. El método de acercarse a su objeto de estudio es un método deductivo que parte de premisas o valores generales ("justicia", "retribución", "libertad", "propor- cionalidad", igualdad"), para llegar a normas más particulares o precisas a un caso concreto, hablamos del método más usual entre los juristas en la actualidad, en el cual se interpretan los contenidos de la ley a partir de su contraste con ciertos valores o principios de justicia.

El pensamiento penal liberal tendría su influencia en el proceso de independencia centroamericano $y$, por supuesto, en todas las codificaciones legales posteriores a esa época. En el ámbito penal, nuestro primer Código penal de 1826 (relacionado en la recopilación de leyes entre 1821 y 1855 del presbítero Isidro Menéndez), sería un referente del pensamiento liberal de la época.

Para Napoleón Rodríguez Ruiz, en su Historia de las instituciones jurídicas salvadoreñas (1951), el Código penal de 1826 no sería más que una adaptación del también liberal Código español de 1822, en palabras del mismo autor

A pesar de ser, ya en aquella época, un código de ideología rezagada, en lo que a las nuevas teorías penales que iba abriéndose paso desde principios de siglo se refiere, no puede menos que considerarse como bastante adelantado, con las modificaciones que nuestros legisladores le introdujeron. (Rodríguez Ruiz, 1951, p. 245) ${ }^{2}$ 
Las causas que motivaron la adaptación del código, también son relacionadas por el autor:

Esta adopción se fundamenta en la ineludible filiación legislativa en que estábamos respecto de España, y en una circunstancia muy particular: don José Mariano Méndez, diputado por el departamento de Sonsonate [...] en donde se discutió durante tres meses el Código Penal español, influyó para que este se adoptara en El Salvador, y fue nuestro connacional, don José Mateo Ibarra, que estaba en Madrid, quien trajo a esta capital, San Salvador, el primer ejemplar del Código, siendo así conocido por los encargados de dictar las leyes en nuestro país (Rodríguez Ruiz, 1951, p. 245).

Como decíamos, si partimos de esta relación entre ambos Códigos, que se corrobora con la simple comparación capitular entre los mismos, debemos concluir que nuestra primera legislación penal posee una fuerte influencia del pensamiento liberal. Lo anterior puesto que el Código español de
1822 (decretado por las Cortes en junio y mandado a promulgar el nueve de julio de 1822) es una legislación que en términos de Zaffaroni, constituye una "obra penal del liberalismo español de la época”, punto que ratifica García García (1999), para quien:

Su promulgación tiene lugar en 1822, esto es, dentro de la segunda experiencia constitucional que conoció nuestro país al amparo de la constitución de 1812 [...] nos encontramos con los liberales en el poder, y con sus planteamientos regulados en ese texto constitucional. (p. 343)

Volviendo a Zaffaroni, se trata de una codificación con una importante presencia del pensamiento francés, aunque también con aspectos originales, reconociéndose ideas de Filangieri y Manuel de Lardizabal y Uribe (Zaffaroni, 2000, p. 41).
En ese sentido, nuestro primer Código penal de 1826, inicia con una declaración de principios que limitan el poder penal del Estado, tal como sugería Beccaria, en su Dei delitti e della pene, principios todavía vigentes en nuestro Código actual, principios tales como: la necesidad de dolo ("a sabiendas y con mala intención") 
o culpa en la realización del delito (artículo 1, lo que conocemos en la actualidad como "principio de dolo o culpa”); la prohibición de imposición de pena que no se encuentre previamente en la ley (referencia al principio de legalidad, artículo 5), relacionando penas diferenciadas entre delitos consumados y tentados (una forma de proporcionalidad, artículo 7), proscribiendo (salvo casos especiales que determine la ley) la sanción penal al pensamiento y resolución de delinquir aún no exteriorizada (una expresión del principio de culpabilidad, artículo 9), regulando algunas formas de error de prohibición (al menos en caso de extranjeros transeúntes o domiciliados por menos de tres meses en el país, artículo 11) y de inexigibilidad de otra conducta (un hacer "forzado en el acto por alguna violencia material", artículo 24), y dejando exentos de responsabilidad penal a los inimputables ("sin discernimiento y malicia", o bien "en estado de demencia o delirio"), ya sean menores de 14 años o mayores de edad (artículos 27 y 29, lo que conocemos como principio de responsabilidad en sentido estricto) (Menéndez, 1956, pp. 386-512).

Se trató además de un Código penal con una parte general corta en comparación a su parte especial, conteniendo la primera parte 130 artículos en cinco capítulos: 1) De los delitos y culpas, 2) De los delincuentes y culpables, 3) Penas y sus efectos, 4) Graduación de delitos y penas, y 5) Reincidencia, contrastando con una voluminosa parte especial de aproximadamente 540 comportamientos perseguidos, que a diferencia de nuestra parte especial vigente iniciaba con los delitos que protegían bienes jurídicos colectivos, para luego regular los delitos que protegen bienes jurídicos individuales.

El delito para ser sancionado requería ser una manifestación de voluntad libremente realizada (como todo texto liberal o "clásico", el libre albedrío es parte fundamental del actuar criminal), el mismo artículo 1 de dicho Código penal consideraba como delito "todo acto cometido u omitido voluntariamente", y todo acto voluntario como "cometido a sabiendas y con mala intención", incluso en la regulación culposa de la responsabilidad se hablaba de un actuar que el autor "puede y debe evitar" (artículo 2), o bien en la que tiene "conocimiento de exponerse a violar la ley", la posibilidad de elegir es entonces un elemento fundamental.

La libertad y consecuente culpabilidad era tan fundamental para la existencia del delito, que el Código conocía una amplia gama de situaciones en las que se eximía de pena por faltar esta libertad, para el caso, se establecía que "en ningún caso puede ser considerado delincuente ni culpable" si cometía una acción "forzado en el acto por alguna violencia material” (artículo 
24), en el caso del menor de ocho años "tampoco puede ser considerado como delincuente o culpable" (artículo 26), ${ }^{3}$ ni tampoco tenía tal calidad el que cometía su actuar "hallándose dormido, o en estado de demencia o deliro, o privado del uso de su razón de cualquier otra manera independiente de su voluntad", en estos casos no había pena y aún no se conocía la expresión "medida de seguridad".

En cuanto a las consecuencias jurídico-penales que regulaba el código penal de 1826, la pena era la única consecuencia a la comisión del delito, ${ }^{4}$ y la misma podía ser de tres tipos: corporales, no corporales y pecuniarias. El espíritu humanista del pensamiento ilustrado no caló lo suficiente como para evitar una regulación de penas verdaderamente violentas, lo que también sucedía con el Código penal español de 1822, recordándonos Anton Oneca, que si bien es cierto que dicha legislación consideraba la educación del delincuente como fin de la pena, "la preferida es la (prevención) general, por medio de la intimidación" (Anton Oneca, 1965, p. 277), en el mismo sentido Zaffaroni, para quien dicho Código es un "texto retributivo y ejemplificador, pero sin la extremada crueldad del código Napoleón" (Zaffaroni, 2000, p. 42).

El Código penal salvadoreño de 1826 no varió ni un ápice en la dureza de su legislación modelo y conoció castigos verdaderamente inhumanos desde nuestra perspectiva actual, castigos como la pena de muerte por garrote, la infamia, la pena perpetua, la obligación de observar la pena de muerte y la vergüenza pública. La declaración de infamia consistía en ser declarado indigno del nombre de salvadoreño (artículo 31), la de vergüenza pública en la obligación - por espacio de una hora - a estar atado a un palo de "la plaza más pública del pueblo en donde cometió el delito" (artículo 66).

En el caso de la pena de muerte, se trataba de un castigo ceremonioso, siempre público, entre las 11 y 12 de la mañana, el condenado debía ser conducido a un cadalso de madera o mampostería sobre una mula, vestido con una túnica negra, ojos tapados y atado de manos; en caso de ser un asesino, la túnica era color blanco manchada de sangre, y con una soga al cuello. En todos los casos, el condenado a morir debía llevar un cartel con letras grandes que anunciaba el delito cometido, llevándolo tanto en su pecho como espalda (artículos 41 y 42). Una especie de "sorteos de la muerte" eran regulados en caso de que el número de condenados a muerte superase las tres personas, si ese era el caso, sólo se aplicaría la mortal pena a tres personas, el azar decidiría cuáles, si el número de condenados llegaba a diez, los perdedores serían cuatro, aumentando en uno el número por cada 
diez condenados a muerte que se iban sumando (artículo 109). Ahora bien, ni siquiera esta buena fortuna libraba a los ganadores de realizar "trabajos perpetuos" luego de ser obligados a presenciar la ejecución de quienes no eran favorecidos por el azar.

Como ya mencionamos, se trata de sanciones que bajo nuestros están- dares actuales fácilmente pueden calificarse como inhumanas, pero que en aquel entonces no parecían tan alejadas de las tasas de violencia que acostumbraba utilizar el sistema colonial y con el cual no fue posible romper en su totalidad, para el caso, Coralia Álvarez caracteriza dicho período colonial como un espacio de terror, un período en el cual:

\begin{abstract}
[....] se vivía con temor. Para los tributarios de la corona española, que habitaban los pueblos de las provincias de San Salvador y Guatemala, el miedo mayor y más persistente era el que el propio régimen imperante inducía en ellos, con fines de control social y político. El ejercicio del poder se hacía presente en la vida cotidiana de la mayoría a base del castigo público, la amenaza de castigo y de los instrumentos asociados a estas presiones, entre los cuales resaltaba el látigo. (Gutiérrez Álvarez, 2007, p. 43)
\end{abstract}

Para la misma autora, entre los medios con que se administraba el miedo, sobresalía el tormento por azotes, el castigo por antonomasia de los indios: "Hombres mujeres y niños podían ser azotados por cualquiera, en cualquier momento $y$ por el motivo más fútil", (Gutiérrez Álvarez, 2007, p. 39) castigo que podía devenir en cualquier momento, por cualquier razón, por motivos tales como quejarse ante tribunales superiores, haberse reunido para presentar quejas a la audiencia, por cuestiones domésticas, riñas o infidelidad e incluso por causas económicas.
Al Código penal de 1826, le seguirían otras tres codificaciones penales que harían pocas variaciones en cuanto a su estructura fundamental: una fuerte declaración de principios que limitaban el poder, una noción de delito basada en la ley y la existencia de culpabilidad, y la pena como consecuencia jurídica principal (sino la única) frente al delito, pena que se dosificaba proporcionalmente al daño cometido, al grado de participación o la culpabilidad del autor. En otras palabras, hablamos de legislaciones con una clara impronta liberal y conformes a los principales postulados de la llamada "escuela clásica". 
Quizá lo más importante en cuanto al resto de codificaciones legales liberales sería la progresiva humanización del castigo, el Código penal de 1859 (inspirado en el Código penal español de 1848) suprimió la pena de infamia; mientras que el Código penal de 1881 (inspirado en el Código penal español de 1870) no hizo cambios sustanciales en este punto, pero el Código penal de 1904 eliminó el sorteo en caso de existir varios condenados con pena de muerte, ${ }^{5}$ la exhibición de los presidiarios arrastrando cadenas al momento en que salieran a trabajar en obras públicas, ${ }^{6}$ las penas de extrañamiento, relegación, confina- miento y destierro, ${ }^{7}$ y finalmente la pena de represión. ${ }^{8}$ Por lo demás, se mantiene la misma idea de delito y la pena sigue dominando el panorama de las consecuencias punitivas.

Sin embargo, resulta curioso que paralelamente al desarrollo de esta legislación de corte liberal, mesurada por principios ilustrados, se desarrollaba saludablemente como parte del sistema penal salvadoreño, formas de castigo y punición que renunciaban al paradigma de culpabilidad por el hecho y servían de antesala a un discurso antagónico al de la escuela clásica: el positivismo penal.

\section{El derecho penal de autor y la alargada sombra del positivismo penal en nuestra legislación}

El derecho penal de autor y el peligrosismo penal positivista no son lo mismo, pero se trata de conceptos que fácilmente se reconducen uno al otro. Mientras que el derecho penal de autor tiene la tendencia a castigar lo que el autor es, y no lo que hace, el peligrosismo penal positivista consiste, entre otras cosas, en la persecución penal de una persona por presentar cierto patrón o forma de vida que se presume peligroso para la sociedad, y que por ende se reprime independientemente se verifique alguna exteriorización criminal o resultado concreto. Aunque sean conceptos diferentes, bien puede decirse que ambas figuras nos llevan al mismo lugar.

La legislación penal salvadoreña ha recurrido al derecho penal de autor y el peligrosismo penal por más tiempo del que ha prescindido de estas figuras, al final, si se mira con atención el desarrollo de nuestra legislación punitiva, el retorno en los últimos años al peligrosismo penal y el derecho penal de autor, a través de figuras manoduristas como la ley antimaras, no constituye otra cosa que "un retorno a casa". Es posible distinguir varios discursos que justificaron el castigo por la personalidad (y no la actividad) 
en el curso de nuestra legislación penal, los primeros en ser utilizados giraban en torno a la apelación al progreso, o bien conservar el orden o el funcionamiento social, mismos que con el paso del tiempo, les fue añadido el muy influyente y refinado discurso de la escuela positivista del derecho penal, del cual todavía conocemos resabios e invocaciones en la actualidad. En suma, ambos discursos avalaron lo que sería una vigencia ininterrumpida del derecho penal de autor y el peligrosismo por más de 150 años en nuestro país. Analicemos a continuación cada uno de estos discursos.

\title{
3.1 Leyes agrarias, de vagancia y policiales
}

\begin{abstract}
Como hemos mencionado, el derecho penal de autor se encuentra proscrito en nuestros primeros códigos penales de corte liberal, es decir, en los códigos penales entre 1826 y 1904, en los cuales la responsabilidad criminal exigía como regla general un hecho
\end{abstract}

exterior, con un resultado también verificable en el mundo exterior, realizado de forma dolosa, incluso el Código penal de 1826 realizaba una suerte de transcripción del Cogitationes poenam nemo patitur de Ulpiano, afirmando que:

\begin{abstract}
El pensamiento y la resolución de delinquir, cuando todavía no se ha cometido ninguna ejecución para preparar o empezar el delito, no están sujetos a pena alguna, salvo la sujeción a la vigilancia especial de las autoridades en los caso que la ley determine. (Artículo 9).
\end{abstract}

La proposición al delito también era la excepción, y cuando se realizaba sin ser aceptada o sin constituir un delito tentado, no había sanción alguna "sino en los casos que la ley lo determine expresamente" (artículo 6). Sin embargo, esta regulación contrastaba con las leyes especiales, códigos de policía y leyes agrarias de la época, mismas que no guardaban reticencia a la hora de perseguir y castigar a vagos, ociosos, fulleros, tahúres y prosti- tutas, no por lo que hacían, sino por lo que eran. Se trataba de normas que aunque formalmente estaban fuera del Código penal, poseían la consecuencia más distintiva del mismo, la capacidad para reducir al condenado violentamente y privarlo de libertad.

Existieron varias de estas normas y leyes especiales en nuestra legislación, por citar las que se encuentran en la recopilación de leyes de Isidro 
Menéndez, puede mencionarse el "decreto legislativo de 29 de abril de 1825 , sobre vagos, coimes y mal entretenidos" (Menéndez, 1956, pp. 205-206), según lo cual se "perseguirán a los vagos, holgazanes, mal entretenidos y coimes considerándolos suspensos en los derechos de ciudadanía, y los reducirán a prisión" (artículo 3). La legislación facultaba a sus aplicadores (jefes políticos, alcaldes y regidores de todas las municipalidades) para realizar "levas" frecuentes, a efectos de "recojer [sic] a los que no tienen ocupación, no ejercen su oficio, o no tienen modo de vivir conocido", e incluso permitía ingresar a la morada ajena a efectos de "ejecutar la prisión de los conocidamente vagos", pudiendo allanarse un inmueble aun frente a la resistencia del "amo de ella" (artículo 12) en busca de los perseguidos.

Al anterior decreto legislativo le siguió el "reglamento de policía, decretado por el Gobierno, en 12 de mayo de 1843" (Menéndez, 1956, pp. 206-209) donde las levas, antes potestativas, se volvían una obligación, y los alcaldes, regidores y jefes de policía:

Son obligados, sin escusa ni pretesto [sic] alguno, a rondar los lunes y jueves de cada semana, desde las siete de la mañana en adelante, por estanquillos, billares, casas de juego y reuniones por las calles públicas, para aprehender a todos los que se encuentren ebrios, portando armas prohibidas, y jentes [sic] sin ocupación ni oficio, ni un modo de vivir conocido.

Más adelante proporcionará continuidad a la anterior normativa un mejor detallado "reglamento de policía” (Menéndez, 1956, pp. 210-215), decretado el seis de agosto de 1854 , en el cual ya se aprecia una diferenciación capitular sobre las formas proscritas de conducir la vida. Para el caso, "el delito de vagancia" (como fue relacionado por el artículo 2 del referido reglamento), y la mendicidad son formas de vida perseguida con sanciones de hasta 15 días de obras públicas, la primera ocasión, y dos meses en caso de reincidencia, haciéndose una excepción en caso de que la vagancia o mendicidad fuese ejercida por una mujer, en cuyo caso la sanción debía cumplirse en una cárcel pública. La "ebriedad de profesión" era sancionada con 15 días de obras públicas la primera ocasión y dos meses en caso de reincidencia (artículo 7), lo que variaba en el caso de las mujeres, que por esta forma de vida merecían la prisión.

El reglamento también mencionaba ciertos comportamientos peligrosos como los juegos prohibidos, la fabricación y venta de aguardiente clandestina y chicha fuerte, faltar a 
los contratos en el caso de los artesanos y jornaleros, e incluso, desertar de las haciendas o de las casas de sus amos en el caso de los domésticos.

La aplicación del Reglamento de Policía quedó en manos de los jueces de Paz y alcaldes de los respectivos poblados, aunque luego se consideró que dicho control debía ampliarse a las zonas despobladas, naciendo el "Reglamento de Policía Rural" (Menéndez,1956,pp. 215-221), decretado por el gobierno el 24 de julio de 1855 , y en el cual surgía la figura del "inspector de policía", un funcionario nombrado por el gobierno ${ }^{9}$ que tenía "jurisdicción preventiva con los jueces de paz y alcaldes de los pueblos de sus respectivos departamentos".

Dentro de las competencias concedidas al inspector de policía figuraba perseguir "constantemente en los campos, caminos, haciendas, hatos, valles y reducciones donde no haya municipalidad", a los ladrones, vagabundos, mujeres holgazanas y traficantes en artículos vedados, entre otros. Así también estaba facultado a requerir "a los habitantes de los campos y reducciones de la clase de trabajadores, para que les presenten periódicamente los boletos de los dueños de las haciendas y labores por mayor, en que conste que están ocupados y guardando buena conducta".
Explicar la razón de este tipo de normativas en un contexto social post-colonial resulta un poco más difícil, sobre todo tratándose de un período influenciado por la filosofía ilustrada francesa, o las amplias libertades de la revolución norteamericana. De nuevo, debemos recordar que el proceso de independencia centroamericana no representó un rompimiento en todos los campos, para el caso, ya hemos mencionado que el Código penal de 1826 era una transcripción en casi todos los sentidos del Código penal español de 1822, mientras que la Constitución de la República Federal de Centroamérica fue diseñada a la medida de la Constitución de Cádiz de 1812.

Por otra parte, también debemos recordar que nos encontramos en un período histórico bastante caótico y convulsionado, que busca desesperadamente sentar las primeras bases de un modelo económico, político y social que sea sostenible en el tiempo. Por citar algunos datos sobre este punto, debe recordarse que apenas tres años antes de la promulgación del primer Código penal (1826), tropas mexicanas se tomaron San Salvador para integrarnos al “Imperio del septentrión”,y dos años antes de la misma fecha, la provincia salvadoreña se había constituido como parte de una endeble República Federal Centroamericana, sin contar que para ese entonces, San Salvador estaba a las puertas de una 
guerra civil entre los así llamados "liberales" y "conservadores". Citando a Héctor Lindo Fuentes en este punto, quien a su vez se apoya en Alejandro Marure, "entre 1824 y 1842 el ejército del Estado de Guatemala se vio envuelto en cincuenta y un batallas, el de El Salvador en cuarenta, el de Honduras en veintisiete y el de Costa Rica en cinco" (Lindo Fuentes, 1993, pp. 157).

Entonces, estamos hablando de un momento histórico en el cual era necesario mantener a toda costa una endeble sensación de orden en la población, más aun, es necesario mantener el débil funcionamiento del sistema económico heredado de la colonia, un sistema que depende de la tierra y que se mantenía con el sudor y trabajo del campesino salva- doreño de aquel entonces, al cual la vagancia, la ociosidad y ebriedad amenazaban su "productividad".

Finalmente, no debe olvidarse que el pensamiento ilustrado centroamericano siempre tuvo mucho de elitista y autoritario, si bien es cierto, la independencia generó cambios para todos los sectores de la sociedad salvadoreña, estos cambios no generaron beneficios en la misma medida. La ley penal, que es un reflejo del sistema político y económico, tampoco tuvo reparos en manejarse a "dos velocidades", la primera para el ciudadano "decente", y la otra para el mendigo, ebrio de profesión o el vago. Esta falta de igualdad es expresada por Eugenia López Velásquez en los siguientes términos:

Al efectuarse la independencia, en las nuevas naciones, los grupos de poder impulsan los cambios que requerían y que el despotismo ilustrado no pudo hacer. Bajo la fuerza de un patriotismo criollo y mestizo, como un discurso de nación, se continuará una práctica de violencia y despojo de tierras. Desde esta perspectiva se encuentran explicaciones sobre porque en El Salvador, en la región y en toda América Latina, en las antiguas colonias no prosperó la parte social del liberalismo, que proponía acabar la pobreza y provocar la felicidad. Lo que se sostuvo fueron los intereses económicos y comerciales de los grupos de poder y el sentimiento de superioridad y desprecio racial frente a los pueblos indios, que anulaba cualquier sentimiento de comunidad o solidaridad de sociedad dominante frente a los pueblos indios y frente a los sectores más pobres. (Velásquez, 2015, p. 33) 
En el mismo sentido, Lowell Gudmundsun dice:

[...] en todos estos casos la norma era que las elites pelearan entre sí sin cuartel, pero que cerraran filas cuando se trataba de suprimir todo tipo de movimientos de clases subalternas que amenazaran echar abajo esta contienda política predominantemente intraclasista o intraoligárquica de liberales frente a conservadores. (Gudmundsun, 1993, p. 210)

\begin{abstract}
En suma, bajo las narices mismas de las codificaciones liberales comienza a gestarse un derecho penal de autor con rasgos claramente autoritarios, un derecho de autor que,

Siguiendo las líneas planteadas por Iñaki Rivera (2005, p. 55) las líneas fundamentales del positivismo penal pueden ser sintetizadas en los siguientes presupuestos:
\end{abstract}

\title{
3.2 El positivismo penal
}

a. Una metodología de acercamiento a su objeto de estudio (el delito y el delincuente) que emula la metodología de las ciencias naturales. Es decir, la observación y estudio cuantitativo de casos particulares para la posterior formulación de reglas generales (método inductivo), sustituyendo la interpretación de principios generales para extraer consecuencias particulares (método deductivo, usual en las ciencias jurídicas y el utilizado por la “Escuela Clásica”). Si esta absolutización de las ciencias naturales en las ciencias sin embargo, aún no ha alcanzado su expresión más acabada, o al menos más "científica" que vendría de la mano con el positivismo penal. sociales representó los primeros pasos de la "sociología", en el campo criminal la presencia del positivismo representaría el nacimiento de la "criminología", es decir, aquel conocimiento que busca deducir las causas y efectos de la criminalidad. Se dejan de lado conceptos o referencias que aludan a realidades que no se puedan medir, o que estén fuera del mundo objetivo (positum en latín viene de lo "puesto" o lo "dado"), hasta ese momento usuales en los códigos penales, palabras como "culpabilidad", "libre albedrío", "mal", "pena", entre otras tantas a las que recurría la escuela clásica.

b. Una visión del delito como fenómeno con origen biológico (positivismo lombrosiano), o 
bien, producto de condiciones sociales (por ejemplo el positivismo de Ferri), verificables $y$ mesurables, y que por ende permiten realizar un juicio de proyección sobre la criminalidad a futuro, así como el "tratamiento" o la "profilaxis" correspondiente.

c. Una visión de responsabilidad determinista, en donde el delincuente es prisionero de una causalidad biológica 0 social que le compele a delinquir. Frente a este "delincuente natural" el Estado puede válidamente protegerse sin necesidad de esperar la exteriorización del comportamiento, o la lesión de bien jurídico alguno.

d. Si el delito es una especie de situación morbosa o anomalía en la personalidad del delincuente, y la sanción constituye su cura, esta sanción no puede comprenderse como otro mal, y pasa a convertirse en un remedio, una suerte de bálsamo curativo o tratamiento que repara la enfermedad presente en el cuerpo del delincuente, previniendo a su vez el "contagio" o expansión de la enfermedad en el resto del cuerpo social. Por supuesto, la "medicina" o "tratamiento" puede durar tanto como se prolonga la enfermedad, haciendo que las medidas perpetuas o indetermi- nadas sean aceptables para el positivismo penal.

En síntesis, para las corrientes positivistas, el delito o el daño al bien jurídico no es más que una manifestación externa, contingente y accesoria de una forma de vivir peligrosa y disfuncional, uno de los muchos síntomas que expresa la enfermedad, pero que en ningún caso se reduce a ella ¿Porque esperar una indeseable manifestación de la enfermedad cuando es tan palpable la condición que la ocasiona? Se preguntan los defensores de estas posturas, que corren apresurados a administrar el "remedio" que protegerá la sociedad de las señales - síntomas - de un delito - enfermedad - tan eminente como grave.

Sin duda, el exponente más conocido del positivismo penal fue el médico, psiquiatra y criminólogo italiano Cesare Lombroso, quien luego de realizar al mejor estilo del método científico, innumerables anotaciones y análisis de casos que conoció durante su práctica médica (Lombroso fue director del manicomio de Pesaro) terminó concluyendo que la delincuencia se debía esencialmente a causas de origen biológico o natural que actúan en el cuerpo del delincuente. Gina Lombroso nos narra este proceso justo cuando atravesó un momento fundamental, el análisis del cráneo de Vilella (1871): 
Mientras estudia a los criminales en masa en las estadísticas, y personalmente con sus ojos y con la ayuda de sus estudiantes, desaparecen los límites entre la locura y el delito que él quería fijar. Los criminales presentan muchas anomalías, así como las presentan los locos -y aún más graves y evidentes-; pero él no sabe cómo coordinarlas, cuando una mañana, abriendo el cráneo de un famoso bandolero, Vilella, que tenía ya 70 años y se había escapado de los gendarmes corriendo ágilmente por los montes, Lombroso encontró en la base del cráneo una foseta occipital media. También los que no han hecho estudios médicos saben que nuestro cerebro está dividido en dos hemisferios y que en el cráneo, casi para separarlos, hay una cresta mucho más pronunciada en la base: cresta occipital media, que se irgue donde en las aves se presenta una fosa destinada a contener un tercer lóbulo medio. Ahora bien, en aquel cráneo, precisamente en el lugar de la cresta occipital, se presentaba una fosa, tan lisa y exenta de vasos inflamatorios que parecía haber sido como receptáculo a un tercer lóbulo medio, como se ve en los embriones en el tercero y cuarto mes, y normalmente en las aves; anomalía rarísima que Lombroso nunca más debía encontrar en aquella proporción.

Viendo aquella fosa -escribe Lombroso-, me apareció bruscamente, como en una amplia llanura bajo un horizonte infinito, aclarado el problema de la naturaleza del delincuente, que debía reproducir en nuestros tiempos los caracteres del hombre primitivo hasta los carnívoros.

Esta era la razón de los pómulos salientes, de la fosa temporal, de las mandíbulas voluminosas, de todas las analogías que había encontrado entre los delincuentes, los salvajes, los enajenados y los hombres prehistóricos: todos representaban estadios sobrepasados de la evolución. Entre los locos y los delincuentes no hay diferencia de calidad sino sólo de intensidad. (Lombroso, 2009, pp. 97-98. $)^{10}$

Para 1880 , se estaría fundando la revista Archivo de psiquiatría, antropología criminal y ciencias penales para servir al estudio del delincuente, que sería la plataforma desde la cual Lombroso y su escuela positivista estarían publicando sus principales hallazgos. Por su parte, en 1885 , las tesis del italiano serían el objeto de discusión en el Primer Congreso de Antropología Criminal celebrado en la ciudad de Roma. Con su obra, Lombroso impactó profundamente el pensamiento europeo de su época $y$, por ende, no tardaría en hacerse sentir en Latinoamérica. 
Por su parte, Beorlegui narra que el desembarco del positivismo (como sistema general de pensamiento) en Latinoamérica, se desarrolla en la segunda mitad del siglo
XIX, y constituye una de las fases más importantes e influyentes en la historia de las ideas de nuestros pueblos, esto tras:

Representar el primer intento, tras de la escolástica, de proponer un sistema positivo y completo para la situación hispanoamericana. Las demás teorías anteriores se habían contentado con superar y criticar el escolantismo conservador, pero no tuvieron pretensión de constituir una alternativa global. (Beorlegui, 2006, pp. 265-266)

En cuanto a la faceta penal del positivismo, es decir, el positivismo penal esbozado, Zaffaroni encuentra sus primeros ecos en los que denomina primer y segundo desembarco de textos y códigos europeos en Latinoamérica. Respecto a este "segundo desembarco" realizado en la medianía del siglo XIX (en el cual se diseminan códigos como el de Baviera de Alemania, el de Zanardelli de Italia y los códigos españoles de $1848-1850$ y 1870 ), el profesor argentino destaca como se "transportaron a América los primeros impulsos del positivismo criminológico italiano y francés, pudiendo afirmarse que es el periodo de fundación de la criminología Latinoamérica por obra de médicos alienistas y legistas" (Zaffaroni, 2000, p. 29).

Por su parte, Rosa del Olmo nos recuerda como en los últimos 15 años del siglo XIX, Latinoamérica experimentó un claro ascenso de la criminología positivista mediante la creación de sociedades científicas y la publicación de libros y artículos de la mencionada tendencia, publicaciones como Los principios fundamentales de la escuela positivista de Francisco Ramos Mejía (Argentina) en 1888; El método positivo en derecho penal de Javier Prado Ugarteche (Peru) en 1889; La escuela antropológica y sociológica criminal ante la sana filosofía de Godofredo Lozano (Argentina) en el mismo año que el anterior; Criminología y derecho de Clovis Bevilaquia (Brasil) en 1896; Epilepsia y delito de Afranio Peixoto (Brasil) en 1899, entre otros (Olmo, 1987, p. 136).

Producción bibliográfica que tuvo eco en los recintos universitarios, como nos recuerda la misma autora citando la Facultad de Jurisprudencia de México (1889), en la cual Miguel Macedo hace referencias a la escuela positivista en su Cátedra de Derecho Penal, en Argentina, donde se realiza un primer curso de Antropología y Sociología Criminal (1897) impartido por el médico Francisco de Veyga, o la 
Cátedra de Antropología y Ejercicios Antropométricos (1899) en la carrera de Derecho de la Universidad de La Habana, en manos del antropólogo Luis Montañe (Olmo, 1987, p. 136).

La influencia del positivismo criminológico en Latinoamérica todavía era vigorosa para 1938, año en que se celebraría el Primer Congreso Latinoamericano de Criminología, realizado en la ciudad de Argentina, y en el cual se hicieron presentes más de 600 latinoamericanos, tratándose entre otros temas oficiales: "La valoración de los factores biológicos y sociológicos en las reacciones antisociales de los menores", "la preparación científica del juez del crimen”, “los índices médico-psicológicos y legales de peligrosidad" $\mathrm{y}$ "la peligrosidad como fundamento y medida de la responsabilidad" (Olmo, 1987, p. 160).

En el caso salvadoreño, a finales del siglo XIX terminaba para nuestro país "la larga espera", produciendo la consolidación en el poder de los así llamados "liberales", que básicamente mantendrán el modelo económico agrario con la diferencia de buscar una mayor apertura comercial, misma de la cual despunta la exportación del café que viene a sustituir al añil, giro económico que se vio acompañado desde sus inicios por cambios en la legislación nacional. ${ }^{11}$ Lo que más nos interesa durante este período es que desde el púlpito académico comienza a legitimarse el positivismo penal europeo, que con un tono más científico y objetivo, poco a poco fue sustituyendo a cualquier otro discurso en el combate al delito, hasta finalmente insertarse en la Constitución de la República de 1950, a través de un resabio que aún se mantiene en nuestra Carta Magna vigente. Profundizando sobre este punto, el profesor Sajid Herrera encuentra a finales del siglo XIX, referencias y fragmentos del discurso del positivismo penal dentro del debate relativo a la modernización de las prisiones; un debate en el cual se entrecruzó el discurso más humanitario y progresista con el más académico y positivista debate desarrollado principalmente en la revista La Universidad de la Universidad de El Salvador, para aquel entonces, único centro de educación superior en nuestro país (Herrera, 2007, pp. 207-217). Siguiendo esta línea, podemos encontrar estas ideas en el artículo de Arthur McDonald, "Aplicaciones de la ética a la criminología", quien cataloga el pauperismo y alcoholismo como formas "patológicas" y anormales de humanidad, formas de vida que en esencia no constituyen más que grados "atenuados" de la vida criminal. En tal sentido expone que:

La relación de la criminalidad a las demás formas patológicas y anormales de la humanidad representa tan solo 
uno de sus grados. Si representamos el crimen que es su grado más alto por A6, A5 podremos decir, que corresponde a la locura criminal, y A4, al alcoholismo, quizás $A 3$ al pauperismo, A2 a otras maneras más débiles de ser de la humanidad que caen más especialmente bajo la acción de la caridad y a la idea de mal en general, particularmente en sus formas más suaves. Así, pues, el crimen es la forma más exagerada del mal, pero estas formas son todas esencialmente unas. Tan agua es una gota como un océano. (McDonald, Revista La Universidad, $N^{\circ} 1, p$. 39)

La referencia a conferencias, o la reseña de ensayos en que predominaban matices peligrosistas, fue también utilizada para exponer este positivismo criminológico, este es el caso de la reseña de la obra $L a$ degerazio nella pazzia e nella criminalitá (La degeneración en la locura $y$ en la enfermedad) del doctor y director del manicomio privado de Messina, Lorenzo Mandalari, reseña realizada en la Revista de Derecho y Jurisprudencia en 1901, y en la que se descarta que el libro sea una "discusión doctrinal", calificándose más bien como un "libro de prueba" por la metodología empleada para formular sus conclusiones: "Una serie de casos de locura y criminalidad, estudiados con el método que aconseja la nueva escuela y clasificados científicamente en cuatro categorías". Por supuesto, cuando se habla de "la nueva escuela", se alude a la escuela positivista encabezada por Cesare Lombroso, un pensamiento en el cual:

\section{[...] no es la voluntad la causa determinante de un hecho del hombre, sino que sería el resultado de los elementos combinados de la herencia, del ambiente, de las degenera- ciones morales y patológicas, etc, que hacen al criminal un ser diferente del hombre normal. (B. S., Revista de Derecho y Jurisprudencia, mayo de 1901, p. 39.)}

Finalmente, quien realiza la siempre ha validado los postulados reseña cae en la cuenta de una de Lombroso, afirmando en tal especie de "sabiduría popular" que, sentido que: apriorística e inconscientemente,

El vulgo es sabio cuando al ver a una persona con ciertas especialidades, de los cuales no se cuenta ni se preocupa 
en observar, exclama casi instintivamente: iqué cara de asesino tiene!" [...] Recordemos también aquel adagio, que anda en boca en boca en el bajo pueblo: "Puta la madre, Puta la hija, Puta la manta que las cobija. (B. S., Revista de Derecho y Jurisprudencia, mayo de 1901, p. 40)

La revista La universidad también bilidad, donde describe los princiencontró espacio para la crónica, pales avances del Cuarto Congreso pudiendo citar el trabajo del doctor Internacional de Antropología Manuel Muñiz, Crimen y responsa- Criminal, un evento en el cual:

\begin{abstract}
[...] reaparecieron los italianos, y desde el primer día Lombroso, que rehusó la presidencia de honor por satisfacer sus impulsos de combatividad, afirmó brillantemente su concepción anatómica del criminal. Durante todas las discusiones algunas muy poco tranquilas, ha mantenido con firmeza, con hechos, la verdad de sus teorías. Su compañero Ferri le secundó insistiendo con su talento, tan brillante como sólido, el hacer ver del factor social en la génesis del crimen. (Muñiz, Revista La Universidad, $N^{\circ} 9$, junio 1987, pp. 268-269)
\end{abstract}

Al final de la crónica, el doctor Manuel Muñiz nos recuerda la importancia de estas discusiones, mismas que "han demostrado el actual estado de la antropología criminal". Este positivismo penal, ya palpable en las revistas científicas salvadoreñas del siglo XIX, vendría a cristalizarse en las dos principales legisla- ciones peligrosistas del siglo XX: la "Ley represiva de vagos y maleantes" y la "Ley de estado peligroso". En cuanto a la "Ley represiva de vagos y maleantes", fue publicada en el Diario Oficial (número 165, del 20 de julio de 1940), su promulgación fue justificada por la Asamblea Nacional bajo el siguiente argumento:

Tanto la vagancia como distintas formas de actividades individuales ilícitas, nocivas para el bienestar y tranquilidad sociales, fronterizas con el delito, pero que escapan por sus condiciones a la ley penal, están tomando proporciones alarmantes, lo cual hace necesario que el Estado, en función de su ejercicio de policía dicte medidas destinadas a proteger a la Sociedad contra aquellos sujetos designados como vagos y maleantes. (Diario oficial $N^{\circ}$ 165, tomo 129, 20 de julio de 1940, p. 2,461) 
La ley castigaba dos formas: ser vago y ser maleante, presumiendo que una persona ejercía estas formas de vida al verificarse ciertos patrones de personalidad, para el caso, se consideraban vagos a quienes habitualmente no ejercían profesión u oficio, a los correteros de comercio sin registro, los que fingieren enfermedades o defectos para mendigar, a los buhoneros, entre otras formas de vida (artículo 2), por su parte se consideraban maleantes a quienes sean rufianes, alcahuetes, tahúres, brujos, hechiceros, adivinadores, entre otras formas de vida (artículo 3).

Aunque la ley tenía una clara tendencia peligrosista, existe un elemento que no le permite clasificarse como un producto "puro" del positivismo penal, y es que todavía castigaba a todas estas formas de vida con "penas" de duración determinada (artículo 8), una consecuencia jurídico-penal más propia de la tradición clásica. Así pues, se hablaba de las siguientes consecuencias: la amonestación del director general de la policía o una autoridad similar con promesa de dedicarse a "trabajos lícitos", la detención policial por tres meses $y$, en caso de reincidir en la vagancia o vida de maleante, una nueva detención de seis meses. Todavía no existía en nuestra legislación penal el "tratamiento" o la "medida de seguridad" indeterminada, figuras que surgen con la lógica positivista.

A pesar de lo anterior, se trató de una ley muy efectiva, como nos recuerda Carlos Moreno en La pena de muerte y la persecución de vagos en las políticas antidelincuenciales de El Salvador. Para 1945, recordando a dicho autor, se habían detenido más de 48 mil personas, lo que colocándose en perspectiva, equivaldría a más de la mitad de la población de Cabañas para ese año (Moreno, Revista Identidades, 2011, p. 135).

Por su parte, la "Ley de estado peligroso" sería la expresión más pura del positivismo penal en nuestra legislación salvadoreña, publicada el 25 de mayo de 1953, y regulaba una única consecuencia penal: la medida de seguridad, que aparecía por primera vez en nuestro ordenamiento penal y que podía ser de cuatro tipos: patrimoniales, eliminatorias, de observación y de detención. Consistiendo las patrimoniales en prestar multa, caución o realizar jornadas de trabajo (no hay mucho de "patrimonial" en esta última medida); las eliminatorias en la expulsión del extranjero "peligroso" y las de observación en la obligación de declarar el domicilio, de permanecer o retirarse de deter- 
minado lugar y la de someterse a vigilancia. En cuanto a las medidas "de detención", suponían la pérdida de libertad del "asegurado", pudiendo cumplirse en los siguientes lugares: casas de trabajo, colonias agrícolas, campos de trabajo, casas de reforma y el hospital psiquiátrico.

Como hemos afirmado, se trata de la expresión más pura de la lógica positivista, la delincuencia se considera el estado más avanzado de un padecimiento que inicia con la peligrosidad, por lo que no hay ninguna dificultad en aplicar tratamiento o medida de seguridad a los adultos haraganes, a los menores problemáticos e incluso a los esquizofrénicos. A final de cuentas, todos muestran iguales o similares factores biológicos o ambientales que denuncian su proclividad al crimen. La vida delictual entonces no se elige, sino que es un camino al que me arrojan mis circunstancias personales frente a las cuales debe responderse de la misma manera, de ahí que todos los destinos terminan en el mismo lugar, ya sea casa de reforma, casa de trabajo o el hospital psiquiátrico; todos son centros de "tratamiento", una palabra utilizada en los considerandos de la ley que en tal sentido afirmaba "[...] es necesario emitir una ley que determine los tipos de esas conductas antisociales y peligrosas y las medidas de prevención adecuadas para su tratamiento", 12 con lo que vemos presente un claro rasgo del positivismo penal en la ley, su desdén por la palabra "pena", ausente en dicho cuerpo normativo y en general de la jerga positivista por su carácter moralizante.

Por supuesto, el verdadero "tratamiento" o "medida de seguridad" no puede verse como un mal, sino por el contrario es un bien; una intervención que cura, al constituir la clave de recuperación del enfermo peligroso que no puede elegir su condición o enfermedad, con lo que arribamos a un segundo elemento distintivo del positivismo de la ley: el carácter indeterminado de sus consecuencias. Si la "medida de seguridad" es una ayuda, entonces no se puede detener y, por el contrario, puede continuar tanto como se prolongue la enfermedad hasta que el "asegurado" demuestre "rehabilitación". En tal sentido, el artículo 7 de la ley estableció como únicas medidas de "detención” el internamiento por tiempo indeterminado en casa de trabajo, colonias agrícolas, hospital psiquiátrico, asilo o institución para alcohólicos o toxicómanos, casa de reforma y el campo de trabajo remunerado en beneficio del Estado. El cerrojo era cerrado por el artículo 21, que establecía que las medidas de seguridad 
eran revisables a petición de la parte asegurada, dependiendo del juez, quien era finalmente el funcionario que decidía cambiar la medida, declarar la libertad condicional del asegurado, o bien decretar su libertad y rehabilitarlo mediante resolución motivada. Todo dependía de la voluntad de la autoridad judicial.
Finalmente, en medio de la vigencia de estas dos leyes, conviene explorar la forma más penetrante en que se receptó el positivismo penal criminológico en nuestra legislación, se trata de la recepción constitucional de dicha doctrina, apareciendo en un inciso del artículo 166 de la Constitución de la República de 1950 , y que reza de la siguiente forma:

Por razones de defensa social, podrán ser sometidos a medidas de seguridad reeducativas o de readaptación, los sujetos que por su actividad antisocial, inmoral o dañosa, revelen un estado peligroso y ofrezcan riesgos inminentes para la sociedad o para los individuos.

La justificación de esta inserción debe ser analizada, sobre todo si consideramos dos aspectos fundamentales: primero, el referido inciso sirvió de justificación de la ley de

peligrosidad de 1953, arriba relacionada, tal como se manifiesta en el primer considerando de dicha ley que se expresa en el siguiente sentido:

Que el inciso $3^{\circ}$ del Art. 166 de la Constitución Política estatuye que, por razones de defensa social, podrán ser sometidos a medidas de seguridad reeducativas o de readaptación, los sujetos que por su actividad antisocial, inmoral o dañosa, revelen un estado peligroso y ofrezcan riesgo inminente para la sociedad o para los individuos, y que dichas medidas deben estar estrictamente reglamentadas por la ley y sometidas a la competencia del Poder Judicial.

En segundo lugar, y más importante todavía, el referido inciso constitucional sigue teniendo actualidad, pues ha sobrevivido desde la Constitución de 1950 hasta nuestra Constitución vigente desde 1983, con una redacción idéntica en su artículo 13 en el inciso final. De hecho, esta parte del artículo 13 de la Constitución sigue siendo utilizada con frecuencia para justificar las políticas manoduristas en nuestro país, e incluso fue citado como norma constitucional legitimadora para el retorno (si es que alguna vez se 
fueron) de las leyes de peligrosidad a nuestro país. ${ }^{13}$

Pues bien, tratando de rastrear la justificación que en su momento tuvo el inciso tercero del artículo 166 de la Constitución de 1950, nos encontramos con el acta número 35 del día 8 de agosto de 1950, en la cual se consigna la exposición de motivos del título $X$ que originalmente contenía el inciso en cuestión y que justifica la inserción del mismo en los siguientes términos:

\begin{abstract}
El tercer inciso es nuevo. La Comisión decidió dar cabida a las medidas preventivas de defensa social como medio científico de lucha contra la delincuencia. Muchos paises han dado cabida en sus leyes secundarias a esta clase de medidas. Sin embargo, debe quedar el principio en la Ley Fundamental, porque de otro modo las leyes secundarias correspondientes podrían ser tachadas de inconstitucionales. La Comisión tiene el respaldo doctrinario de los más destacados penalistas de nuestros días. En este orden de ideas, solicitó consejo al Dr. Manuel Castro Ramírez h., catedrático de Derecho Penal de la Universidad de El Salvador. El Doctor Castro Ramírez h. propuso la redacción que, con algunas variantes, aparece en el artículo, y él la tomó de la legislación belga, donde halló la expresión más acabada de la teoría del estado peligroso. (Comisión Coordinadora para el sector justicia. Documentos históricos, Asamblea Constituyente 1950-1951. En Las constituciones de la República de El Salvador 1824-1962, Tomo IIB, pp. 698)
\end{abstract}

Basta leer rápidamente la anterior justificación para caer en la cuenta de su insuficiencia, se trata de una aceptación hueca y acrítica de afirmaciones sin mayor peso de autoridad argumentativa. Se habla de un carácter científico, sin motivar en qué consiste esta ciencia, o las razones o estudios que la sustentan. Peor aún, se habla de un carácter científico en la lucha contra la delincuencia, pero no se razona como tales estudios científicos -que ni siquiera citan- se aplican a nuestro país, a nuestras circunstancias particulares e histó- ricas. Luego, estas razones deben ser avaladas porque son respaldadas por figuras académicas, cuyo trabajo científico en este campo se desconoce, sólo sabiendo que se trata de docentes de Derecho penal que han extrapolado una ley del norte de Europa a Centroamérica.

La fundamentación del inciso tercero del artículo 166 de la Constitución de 1950 no tenía sentido entonces, y mucho menos lo tendrá ahora, se trata de la ciencia 
- o al menos la apelación a éstajugando a ser política, y la política buscando resolver problemas sociales con tanta violencia como tenga a la mano, y que mejor vehículo para reprimir a los peligrosos 0 a quienes piensen diferente que las fórmulas vagas del positivismo ("tahúr", “vago habitual”,"rufian”, entre otras) y sus medidas de seguridad indeterminadas.
Finalmente, debe decirse que el discurso positivista llega a finales del siglo XX en nuestra legislación penal con un ropaje más moderado, cediendo terreno a los postulados de la escuela clásica con los que genera un pensamiento mixto, así pasamos a la etapa del eclecticismo penal que analizaremos en la segunda parte de este trabajo.

\section{Referencias bibliográficas}

- Antón Oneca, J. (1965). Historia del Código penal de 1822. En Anuario de derecho penal y ciencias penales. Tomo 18, España.

- B. S., La degerazio nella pazzia e nella criminalitá. (Mayo de 1901). Revista de Derecho y Jurisprudencia. Tomo III, número 9.

- Beling, E. (2002). Esquema de derecho penal. La doctrina del delito-tipo. Buenos Aires: Librería "El Foro".

- Beneitone, P. (2007). Reflexiones y perspectivas de la Educación Superior en América Latina. Informe Final Proyecto Tuning. América Latina. Bilbao.

- Boerlegui, C. (2006). Historia del pensamiento filosófico latinoamericano. Bilbao, Universidad de Deusto.

- Browning, D. (1998). El Salvador, la tierra y el hombre. San Salvador: CONCULTURA.

- Cardenal, R. (2007). Manual de Historia de Centroamérica. San Salvador: UCA editores.

- Comisión Coordinadora para el sector justicia. Documentos históricos, Asamblea Constituyente 1950-1951. En Las constituciones de la República de El Salvador 1824-1962, Tomo IIB.

- Diario oficial. (1940). Número 165, tomo 129, San Salvador.

- Domingo, R. (2004). Juristas Universales, volumen II. Madrid: Marcial Pons.

- Elbert, C. A. (1998). Manual Básico de Criminología. Universidad de Buenos Aires.

- FUSADES.(2010). El estado de peligrosidad: una figura jurídica olvidada. Revista Estudios Legales, San Salvador. 
- García García, R. (1999). El primer Código Penal español de 1822 y su regulación de la religión católica. Revista Derecho y opinión, N 7, España.

- Gudmundsun, L. (1993). Sociedad y Política (1840-1871). En Héctor Pérez Brignoli (Ed.) Historia General de Centroamérica, Tomo III. Madrid: Ediciones Siruela.

- Gutiérrez Álvarez, C. (2007). El espacio de muerte: el miedo y el terror en los espacios coloniales de San Salvador, Sonsonate y Guatemala. En Los rostros de la violencia. San Salvador: UCA editores.

- Herrera, S. (2007). No que muera, sino que se arrepienta el criminal y viva. En Los rostros de la violencia. San Salvador: UCA editores.

- Jiménez de Asúa, L. (1990). Principios de derecho penal: La ley y el delito. Buenos Aires: Abeledo Perrot.

- Lindo Fuentes, H. (1993). Economía y sociedad (1810-1870). En Historia General de Centroamérica, tomo III. Madrid: Ediciones Siruela.

- Lombroso, N. (2009). Vida de Lombroso. México: Instituto Nacional de Ciencias Penales.

- McDonald, A. (1988). Aplicaciones de la Ética a la Criminología. Revista La Universidad, serie 5. $\mathrm{N}^{\circ} 1$, San Salvador.

- Menéndez, I. (1956). Código penal del Estado, decretado por la legislatura en 13 de abril de 1826. San Salvador: Secretaría de la Presidencia de la República.

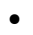

. (1956). Recopilación de las leyes del Salvador en Centro América [1821-1855]. San Salvador: Secretaría de la Presidencia de la República.

- Ministerio de Justicia. (1960). Informe de la comisión de legislación 15 de marzo de 1904. En Códigos penales de El Salvador. San Salvador: Publicaciones de Ministerio de Justicia. (1960). Proyecto de código penal de la república de El Salvador.

- Moreno, C. (2011). La pena de muerte y la persecución de vagos en las políticas antidelincuenciales de El Salvador, 1928-1946. Revista Identidades. San Salvador: Dirección Nacional de Investigaciones en Cultura y Arte.

- Muñiz, M. (Junio de 1987). Crimen y responsabilidad. Revista La Universidad, serie 7. $N^{\circ} 9$.

- Olmo, Rosa del. (1987). América latina y su criminología. México: Siglo XXI editores.

- Pérez, I. de M. (1983). Código penal tipo para Iberoamérica. En Anuario de derecho penal y ciencias penales, Tomo 36. España: Ministerio de Justicia. 
- Ramos Pascua, J. A. (1995). El positivismo jurídico en España. D. Pedro Dorado Montero. En Anuario de Filosofía del derecho XII, España.

- Rivera Beiras, I. y otros. (2005). Política Criminal y Sistema Penal. Viejas y nuevas racionalidades punitivas. Barcelona, editorial Anthropos.

- Rodríguez Ruiz, N. (1951). Historia de las instituciones jurídicas salvadoreñas. San Salvador: Editorial Universitaria.

- Trejo, M. A. (2002). Curso de Derecho Penal Salvadoreño. San Salvador: Editorial Triple D.

- Velásquez, E. L. (2012). Representaciones de los pueblos originarios en la sociedad salvadoreña: siglo XVI a inicios del xx. Las figuras del enemigo. Alteridad y conflictos en Centroamérica. San salvador: Dirección Nacional de Investigaciones en Cultura y Arte.

- Welzel, H. (1956). Derecho Penal. Parte General. Buenos Aires: Roque de Palma editor.

- Zaffaroni, E. R. (2000). Los códigos penales de Latinoamérica. En Los códigos penales de los países de América Latina. México: ILANUD.

\section{Notas}

1 En un análisis de las concepciones curriculares en América latina, el informe final del proyecto Tuning, destacaba que "La dogmática jurídica ha sido la matriz teórica dominante en la mayor parte de las facultades o cursos, con énfasis metodológico en la transmisión de contenidos teóricos por parte del docente y la absorción de éstos por el estudiante. No hay una aproximación sistematizada entre la enseñanza y los procesos de aprendizaje que, en la mayoría de las instituciones, son aún muy conservadores, fundados en una metodología de asimilación acrítica de proposiciones teóricas, o memorización de normas jurídicas" (Beneitone (2007, p. 110-111).

Esta tesis también se confirma en las primeras páginas de la publicación del Ministerio de Justicia, Códigos penales de El Salvador, según la cual el código penal de 1826 "con algunas variantes, fue tomado del Código Penal Español de 1822 y aparece insertado en la Recopilación de leyes patrias del Presbítero y doctor Isidro Menendez". (Cfr. Ministerio de Justicia, Codigos penales de El Salvador, p. 9)

En el caso de los menores infractores, todas las penas, por muy graves que fuesen, eran modi- 
ficadas a la pena de "reclusión", que tenía un máximo de 15 años (artículo 70), consistiendo esta sanción en la obligación de laborar en algún oficio, arte u ocupación en una casa de reclusión (artículo 64).

Aunque en una pequeña parte de la regulación del delito, dedicaba un artículo (el art. 30) a las consecuencias civiles del delito.

5 Según informe de la Comisión de legislación, realizada en marzo de 1904, y conformada por Teodosio Carranza, Manuel Delgado y Salvador Gallegos, tal supresión responde a que "nos parece chocante e inmoral que el legislador fíe al azar el resolver sobre la vida o muerte de los hombres, y porque no existiendo en nada la igualdad absoluta, creemos que nunca han de faltar a los tribunales razones suficientes para establecer en la sentencia el orden de culpabilidad de los reos". (Cfr. Ministerio de Justicia, Informe de la comisión de legislación 15 de marzo de 1904, 1960, p. 28).

6 "La constante exhibición de los presidiarios arrastrando la cadena en las calles de nuestras poblaciones, al mismo tiempo que les quita a los que no están avezados al delito lo poco o mucho que puedan tener de dignidad 0 vergüenza, es un espectáculo indigno de una sociedad que aspira a merecer el nombre de culta y civilizada" (Cfr. Ministerio de Justicia, Informe de la comisión de legislación 15 de marzo de 1904, 1960, p. 28).

7 Según el informe de la Comisión de legislación, estas penas "tienen, a nuestro juicio, el gravísimo inconveniente de que, según la condición social y demás circunstancias del reo, pueden ser para él una pena enteramente ilusoria o un castigo más o menos grave que no guarde proporción alguna con el delito cometido" (Cfr. Ministerio de Justicia, Informe de la comisión de legislación 15 de marzo de 1904, 1960, p. 26).

Según la Comisión, dicha pena tiene el defecto "de carecer de toda eficacia precisamente cuando más convendría que tuviera; es decir, cuando el culpable esta destituido de sentimientos de dignidad y delicadeza" (Cfr. Ministerio de Justicia, Informe de la comisión de legislación 15 de marzo de 1904, 1960, p. 26).

9 Los requisitos para ser inspector de policía eran tener más de 25 años, tener buena conducta, tener alguna propiedad conocida, estar en ejercicio de la ciudadanía y no haber sido encausado por hurto, robo, estupro o violación (artículo dos). 
10 Por su parte, Elbert también se refiere al trabajo de Lombroso en los siguientes términos "El interés científico de Lombroso por las taras genéticas hereditarias o congénitas, que tan reiteradamente observara en locos y delincuentes alterados, fue llevándole gradualmente a la idea de que debía existir una relación de carácter biológico entre la degeneración y los instintos perversos o destructivos. Por esa vía, se acentúa en su pensamiento la sospecha de que el delincuente tiene una tendencia malvada innata ligada a su estructura física y psíquica, que se manifiesta hasta en su fisonomía. En especial, Lombroso fija su atención en caracteres somáticos y biológicos del delincuente, convencido de que atavismo y degeneración se combinan, de modo tal, que en cada delincuente pueden detectarse un buen número de características degenerativas, como la relación peso-altura, la capacidad craneana o características como mirada extraviada, orejas grandes, asimetrías, labios leporinos, granos, etcétera” (Elbert, 1998, p. 49).

11 Recordándonos Browning como las condiciones muy particulares de este nuevo cultivo fueron, por encima de cualquier otra consideración, las principales razones que motivaron la reforma del régimen legal de tenencia y uso de la tierra en función a los intereses de una minoría pudiente que podía apro- vechar dicho modelo, y frente a la cual los valores e instituciones tradicionales de tenencia colectiva de la tierra, representaban obstáculos a vencer. Así, en los albores de este nuevo capitalismo agro-exportador se promulgan: la "Ley de extinción de comunidades" (febrero de 1881), despojando a los indígenas de sus tierras comunales, reforzándose con la "Ley sobre jornaleros y creación de jueces de agricultura" (marzo de 1881), que estaba destinada a reclutar y redistribuir a los indígenas expropiados, de manera voluntaria o forzosa, como peones en las fincas cafetaleras, y la "Ley de extinción de ejidos" (marzo de 1882) que buscaba abolir el sistema ejidal de tenencia de la tierra. Más adelante se dará el nacimiento de la Policía Rural (febrero de 1884) y Policía Montada (marzo de 1889), ambas con el objetivo específico de proporcionar orden en Ahuachapán, Sonsonate y Santa Ana, donde los desalojos habían generado protestas entre campesinos (Browning, 1998, pp. 276-287).

12 El término "tratamiento" aparece en el artículo 4, cuando enlista los destinatarios de la ley, en tal sentido se expresa: "Únicamente podrán ser declarados en estado peligroso y sometidos al tratamiento de las medidas de seguridad establecidas en esta 
ley",y a continuación mencionaba el listado que incluía a vagos habituales, mendigos habituales, ebrios o toxicómanos habituales, rufianes y proxenetas, sujetos pendencieros, sospechosos de atentar contra la propiedad ajena, tahúres, entre otros. La palabra vuelve a aparecer en el artículo 6 , en el cual se habla de las consecuencias a la forma de vida peligrosa: "También será obligatoria una información sobre la conducta del peligroso, para establecer las causas sociales de su peligrosidad y el tratamiento que ha de aplicársele".

13 Para el caso, este inciso constitucional fue citado por el artículo
El estado de peligrosidad: una figura jurídica olvidada, relacionado en uno de los boletines de estudios legales de la Fundación Salvadoreña para el Desarrollo de El Salvador (FUSADES), artículo que según las conclusiones finales del tanque de pensamiento "(...) colige que no hay obstáculo legal para emitir una Ley de Peligrosidad" (FUSADES, Boletín 120, diciembre de 2010, p. 7). La propuesta de implementar leyes de peligrosidad incluso fue retomado por las agendas electorales de algunos partidos políticos de derecha. 